\title{
Psychosexual Dysfunction with Inhibited Sexual Excitement
}

National Cancer Institute

\section{Source}

National Cancer Institute. Psychosexual Dysfunction with Inhibited Sexual Excitement. NCI Thesaurus. Code C34960.

Recurrent and persistent suppression of sexual excitement during sexual activity. 